\title{
Apresentação ao número especial: Teoria de crise e a atualidade da crítica da economia política: uma homenagem ao prof. Eduardo Augusto de Lima Maldonado Filho
}

Presentation to the special issue: Crisis theory and the up-to-dateness of the critique of political economy: a tribute to prof. Eduardo Augusto de Lima Maldonado Filho

Este número especial apresenta dois propósitos mutuamente relacionados um com o outro. O primeiro é homenagear o economista, professor e pesquisador Eduardo Augusto de Lima Maldonado Filho, camarada que se destacou nos estudos sobre concorrência real e na formação intelectual de novas gerações desde a Universidade Federal do Rio Grande do Sul (UFRGS), algo que se nota entre as várias contribuições neste número especial. O segundo é apresentar o debate sobre crise econômica centrado na dinâmica da lucratividade e seus componentes para compreender o processo de acumulação de capital, sua dinâmica, entraves e tendências gerais. Trata-se de perspectiva teórica cujas bases analíticas foram colocadas na crítica da economia política lançada por Karl Marx e Friedrich Engels e que tem se avolumado especialmente a partir da década de 1970, para a qual o prof. Eduardo Maldonado Filho se destacou como um dos precursores em seu desenvolvimento teórico aplicado à economia brasileira.

Isso se nota claramente em sua trajetória de investigação destacadamente a partir de sua tese de doutorado intitulada Profit Rate Differentials in Brazilian Manufacturing Industry, 1973-85, defendido junto à New School for Social Research (atualmente apenas The New School) cuja pesquisa iniciou nos anos 1980 e foi concluída em 1996 (MALDONADO FILHO, 1996). Vale notar que uma parte desta investigação havia sido publicada em português alguns anos antes na revista Ensaios FEE (MALDONADO FILHO, 1989). Nesta pesquisa, o professor examinou os diferenciais de rentabilidade entre

\footnotetext{
${ }^{\text {a }}$ Professor do Instituto de Economia e Relações Internacionais da Universidade Federal de Uberlândia (IERIUFU). E-mail: 1seguram@ufu.br

${ }^{\mathrm{b}}$ Professor do Instituto de Estudos em Desenvolvimento Agrário e Regional da Universidade Federal do Sul e Sudeste do Pará (IEDAR-Unifesspa) E-mail: giliad.souza@unifesspa.edu.br
} 
os setores oligopolista e competitivo da indústria brasileira entre 1973 e 1985 para testar a hipótese de que o setor oligopolista da economia pode auferir lucros superiores ao lucro médio para o período. As evidências encontradas no referido estudo indicam que

\begin{abstract}
não existe um diferencial significativo de rentabilidade entre esses dois setores, como deveria ocorrer caso as indústrias oligopolistas fossem, de fato, capazes de defender suas taxas de lucro numa recessão, através do aumento dos preços. Ou seja, os aumentos das margens brutas de lucro das indústrias oligopolistas, que são captados pelos estudos econométricos sobre o comportamento dos preços ao longo do ciclo, não apoiam a hipótese pós-keynesiana de que esses acréscimos resultam do exercício do poder de mercado por parte das empresas dessas indústrias (MALDONADO FILHO, 1989, p. 262).
\end{abstract}

Essas observações indicam que as tendências de concentração e centralização de capital com o desenvolvimento capitalista não implicam redução da concorrência como sugerem algumas abordagens econômicas. Pelo contrário. A violência da concorrência se evidencia de maneira cada vez mais profunda na medida em que as crises explicitam a natureza classista das sociedades de mercado. $\mathrm{O}$ cerne da problemática reside antes na dinâmica da luta de classes do que no grau de poder de mercado das empresas. Por isso investigar os determinantes da lucratividade, sua relação com as crises e o conflito distributivo são fundamentais para o entendimento do capitalismo contemporâneo.

Weisskopf (1979), Duménil \& Lévy (2002), Basu \& Manolakos (2012) e Basu \& Vasudevan (2013) são alguns exemplos de estudos para a economia estadunidense com dados observados desde 1945. Shaikh (2011), por sua vez, argumenta, à luz da história das crises do capitalismo avançado, que os padrões econômicos observados na história do capitalismo residem no fato de que o motivo de lucro (profit motive) é o regulador principal do comportamento de negócio dos agentes. Mohun (2003) estuda especificamente o caso da Austrália entre 1965-2001. Brown \& Mohun (2011) analisam o comportamento da taxa de lucro para a Grã-Bretanha no período entreguerras (1918-1939). Para a periferia do sistema capitalista, também é presente no debate público análises sobre a tendência declinante da taxa de lucro, como atestam Maito (2015) sobre a Argentina entre 1910-2010, Mariña Flores \& Cámara Izquierdo (2016) em relação ao México desde 1939, e Samudru \& Pratama (2014) com informações desde 1951 para a Indonésia.

Especificamente para o Brasil - e de maneira mais precisa em português - os trabalhos ainda são incipientes. Além da mencionada contribuição de Maldonado (1989), vale notar que Marquetti \& Maldonado \& Lautert (2010) é um dos primeiros, senão o primeiro estudo, a investigar os movimentos da taxa de lucro, seus componentes e a relação com a acumulação de capital no país numa perspectiva de longo prazo. Posteriormente, Marquetti \& Hoff \& Miebach (2020) analisaram a queda da lucratividade como elemento central na produção da recente crise econômica no Brasil, abarcando o período entre 20002016, ao passo que Marquetti et al. (2019) investigaram as possibilidades de mensuração da lucratividade média no Brasil em contexto inflacionário. De maneira geral, esses trabalhos indicam que entre 1953 até a primeira metade dos anos 1990 a taxa de lucro 
apresentou tendência de queda. A partir de então, a trajetória foi invertida, mas em 2003 ainda não tinha sido capaz de ultrapassar o nível de meados dos anos 1980.

Outras contribuições recentes para a economia brasileira contemporânea e que merecem atenção são Bruno \& Caffe (2018), que mostram como a deterioração do cenário macroeconômico a partir de 2014 se devem a fatores estruturais e, portanto, pouco poderiam ser atacados por meio de medidas anticíclicas; Martins \& Rugitsky (2021), por sua vez, demonstram como a crise brasileira da segunda década do século XXI está relacionada a uma compressão dos lucros (profit squeeze, em inglês) observada entre 2009 e 2014. Ambas contribuições reforçam as anteriores e mostram a importância de se investigar de maneira detida os determinantes da lucratividade e da acumulação de capital.

Do ponto de vista teórico, a relação entre a taxa de lucro e a dinâmica da acumulação de capital se dá por meio do papel exercido pela tecnologia no incremento relativo do estoque de capital vis-à-vis o estoque de mão-de-obra empregada na produção. No longo prazo, o desenvolvimento das forças produtivas pressiona as empresas competitivas a empregarem na produção gastos maiores na aquisição de máquinas, equipamentos, pesquisa e desenvolvimento, matérias-primas, aluguéis ou construção de edifícios para a produção, em comparação com os gastos relacionados ao emprego da força de trabalho.

Vale notar, contudo, que existem contratendências que podem afetam estocasticamente a taxa de lucro ou individualmente seus componentes e que operam no âmbito do próprio processo de acumulação de capital, tais como o aumento da intensidade da jornada de trabalho, barateamento relativo do valor da cesta de subsistência da classe trabalhadora e do capital constante, superpopulação relativa de trabalhadores, exportação de capital e expansão do mercado de ações.

No primeiro texto após esta Apresentação, o ensaio de Fernanda Valada Machado apresenta o debate sobre a lei geral da acumulação capitalista e o sentido do progresso técnico nas relações sociais de produção vigentes. Nele, a autora dialoga com debates recentes sobre a relação entre a produtividade do trabalho e a concentração de renda e riqueza do capitalismo contemporâneo, levantando alguns pontos importantes para o debate da economia política, notadamente no que diz respeito à continuidade da acumulação capitalista e o bem-estar da classe trabalhadora.

Em sequência, Lucas Rodrigues discute a centralidade do circuito do capital industrial para o estudo econômico das crises. Nesse sentido, a oposição "capital" e "trabalho" é alçada a posição central para o entendimento das formas concretas de existência do capital industrial. Após isso, Giliad de Souza Silva e Dayani Cris de Aquino esmiuçam didaticamente o problema da reprodução do capital social total a partir dos esquemas marxianos e seus debates. Em ambos é possível notar a emergência das possibilidades de crise como elemento endógeno às condições de reprodução social, as quais não são exatamente as mesmas da ótica do capital individual.

Claus Germer avança, em seguida, propondo uma formalização completa da taxa média de lucro a partir das contribuições de Marx. Nesse sentido, o autor discute o impacto da rotação do capital na formação da taxa média de lucro e procura incorporar o lucro bancário no cálculo do lucro médio das economias reais. Já Leonel Toshio Clemente e 
Eduardo Maldonado Filho procuram desenvolver uma solução empírica para o cômputo do capital fixo no cálculo da taxa de lucro geral por meio de um modelo de mudanças de regime Markoviano para a economia dos EUA entre 1947-2007.

Em outro texto, Lucas Rodrigues, Marcelo Milan e Ronaldo Herrlein Jr. propõem a utilização de uma medida de lucratividade sobre o patrimônio líquido e seus componentes que incorpore a absorção e liberação de capital produtivo, cuja importância teórica havia sido antecipada em língua portuguesa por Maldonado Filho (1982). Se, por um lado, a contribuição de Rodrigues, Milan e Herlein Jr. discute especificamente a economia dos EUA, por outro, Henrique de Abreu Grazziotin, Ana Paula Fornari e Adalmir Antonio Marquetti trazem a discussão para a economia brasileira numa investigação das concepções teóricas e a análise histórica da relação de causalidade entre taxa de lucro e acumulação de capital no Brasil. Os resultados evidenciados se mostraram consistentes com a causalidade de Granger unidirecional da taxa de lucro para a taxa de acumulação de capital no Brasil entre 1953 e 2017, além de reforçarem observações anteriores sobre a tendência geral da lucratividade na economia brasileira contemporânea.

Pedro Henrique F. D. Sampaio, Alessandro Donadio Miebach e Henrique Morrone dão um passo a mais na investigação empírica da economia brasileira contemporânea a partir da crítica da economia política. Para tanto, os autores estimaram variáveis-chave da abordagem, tais como, capital variável, massa de mais-valor, taxa de exploração e lucro desde uma ótica clássico-marxiana. Em tal investigação, constatou-se que, entre $2010 \mathrm{e}$ 2015, houve crescimento das atividades não-produtivas em sua participação relativa da produção e distribuição nacional. Uma das consequências apontadas pelos autores é que se gerou uma quantidade menor de riqueza ao longo do período.

Em ensaio seguinte, Elohá Cabreira Brito e Eduardo Maldonado Filho analisam como a pandemia do COVID-19 escancarou as contradições do capitalismo e reacendeu o debate sobre alternativas no horizonte. No texto, a autora e o autor discutem criticamente duas alternativas que visam colocar o ser humano no centro do sistema socioeconômico: o modo de produção associado e a economia de Clara e Francisco.

Gerard Duménil e Dominique Lévy descem ao concreto para analisarem detidamente o papel do Federal Reserve (FED) dos EUA frente ao aprofundamento da crise econômica desde 2007-2008. Na leitura dos economistas, a continuidade de taxas de juros baixas por parte do FED será alvo de fortes resistências por parte de agentes do sistema financeiro em virtude de sua sustentabilidade no tempo, haja vista o conflito entre interesses privados e o papel de financiador de crédito por parte do FED. Trata-se de uma reflexão que lança algumas luzes para o controverso debate a respeito da teoria da financeirização no estudo do capitalismo contemporâneo.

Para encerrar o número especial, contamos com um texto inédito do prof. Eduardo Maldonado Filho, no qual expõe algumas considerações sobre a atualidade da crítica da economia política no capitalismo contemporâneo. Em sua leitura, ainda que o crescente aumento das desigualdades, da pobreza e destruição ambiental devido às experiências neoliberais, até o momento não se observa o que ele designa por 'crise do pensamento econômico dominante'. Ainda assim, reforça o prof. Maldonado, que a profunda crise 
econômica e social do capitalismo reabre o debate sobre alternativas de desenvolvimento e revela a atualidade da teoria de Marx.

A homenagem proposta é também um reconhecimento em vida pela trajetória intelectual e profissional do prof. Eduardo Maldonado Filho, a qual contribuiu para a formação de inúmeras gerações de professores e pesquisadores da área, como se pode atestar em vários dos trabalhos deste número especial. Tal contribuição se revela fecunda e cuja atualidade cada vez mais é confirmada pela realidade concreta do capitalismo contemporâneo. Isso poderá ser atestado ao longo da leitura dos trabalhos aqui reunidos.

No total, descontando esta Apresentação temos 12 textos inéditos discutindo a temática proposta. Além disso, convidamos os autores e autoras que contribuíram para escrevessem algum comentário sobre um dos textos selecionados para publicação. O objetivo é fomentar o debate propiciando um diálogo qualificado já no próprio número especial, como podem ver pelos 3 comentários ao final.

Sendo assim, a proposta visa somar nesse debate incorporando avanços analíticos e metodológicos para disponibilizar em língua portuguesa uma amostra do atual estágio da linha de investigação sobre teoria de crise e a atualidade da crítica da economia política. Nesse sentido, o número especial tem potencial de contribuição pedagógica para cursos de graduação e pós-graduação, propiciando renovada fonte para o pensamento econômico crítico no país.

\section{Agradecimentos}

Agradecemos a todos e todas que colaboraram para a realização desse número especial, com destaque para pesquisadores do Grupo de Pesquisas em Economia Política (GPEP), cuja ideia nasceu também de conversas e orientações com o prof. Eduardo Maldonado Filho na UFRGS. Este número especial é também fruto do trabalho do GPEP.

\section{Referências}

BASU, Deepankar; MANOLAKOS, Panayiotis T. Is there a tendency for the rate of profit to fall? Econometric evidence for the U.S. economy, 1948-2007. Review of Radical Political Economics, vol. 45, n. 1, 2012. DOI: https://doi.org/10.1177/0486613412447059

BASU, Deepankar; VASUDEVAN, Ramaa. Technology, distribution and the rate of profit in the US economy: understanding the current crisis. Cambridge Journal of Economics, vol. 37, n. 1, 2013. DOI: https://doi.org/10.1093/cje/bes035 
BROWN, Vincent; MOHUN, Simon. The UK interwar rate of profit 1920-1938. Cambridge Journal of Economics, vol. 35, n. 6, 2011. DOI: https://doi.org/10.1093/cje/ber013

BRUNO, Miguel Antonio Pinho; CAFFE, Antonio Ricardo Dantas. Determinantes das taxas de lucro e de acumulação no Brasil: os fatores estruturais da deterioração conjuntural de 2014-2015. Revista de Economia Política, vol. 38, n. 2 (151), 2018. DOI: https://doi.org/10.1590/0101-31572018v38n02a02

DUMÉNIL, Gérard; LÉVY, Dominique. The profit rate: where and how much did it fall? Did it recover? (USA 1948-2000). Review of Radical Political Economics, vol. 34, n. 4, 2002. DOI: https://doi.org/10.1177/048661340203400403

MAITO, Esteban. La acumulación de capital en Argentina 1910-2011. Dissertação (Mestrado) - Curso de Economia Política, FLACSO, Buenos Aires, 2015. Disponível em: https://www.academia.edu/16248324/Maito Esteban Ezequiel La Acumulaci\%C3\%B3 $\underline{\mathrm{n} \text { de Capital en Argentina } 19102011 \text { TESIS DE MAESTRIA }}$

MALDONADO FILHO, Eduardo. Concorrência e diferenciais intersetoriais de rentabilidade: uma análise da indústria brasileira - 1973/85. Ensaios FEE, Porto Alegre, 10(2), 1989.

MALDONADO FILHO, Eduardo. Profit rate differentials in Brazilian manufacturing industry, 1973-85. Tese (Doutorado), Faculty of Political and Social Science, The New School, 1996.

MARIÑA FLORES, Abelardo; CÁMARA IZQUIERDO, Sergio. The structural causes of the severity of the world crisis in Mexico. In SANTARCÁNGELO, Juan E.; JUSTO, Orlando; COONEY, Paul (Eds.). Latin America after the financial crisis: economic ramifications from heterodox perspectives. Ed. Palgrave MacMillan, 2016.

MARQUETTI, Adalmir; MALDONADO FILHO, Eduardo; LAUTERT, Vladimir. The rate of profit in Brazil, 1953-2003. Review of Radical Political Economics, vol. 42, n. 4, 2010. DOI: https://doi.org/10.1177/0486613410375058

MARQUETTI, Adalmir; MORRONE, Henrique; MIEBACH, Alessandro; OURIQUE, Luiz Eduardo. Measuring the profit rate in an inflationary context: the case of Brazil, 19552008. Review of Radical Political Economics, vol. 51, n. 1, 2019. DOI: https://doi.org/10.1177/0486613416689834 
MARQUETTI, Adalmir; HOFF, Cecilia; MIEBACH, Alessandro. Profitability and distribution: the origin of the Brazilian economic and political crisis. Latin American Perspectives, vol. 47, n. 1, 2020. DOI: https://doi.org/10.1177/0094582X19887751

MARTINS, Guilherme Klein; RUGITSKY, Fernando. The Long Expansion and the Profit Squeeze: Output and Profit Cycles in Brazil (1996-2016). Review of Radical Political Economics, vol. 53, n. 3, 2021. DOI: https://doi.org/10.1177/0486613420982083.

MOHUN, Simon. The Australian rate of profit 1965-2001. The Journal of Australian Political Economy, n. 52, 2003. Disponível em: https://search.informit.org/doi/10.3316/ielapa.200401321.

SAMUDRO, Bhimo Rizky; PRATAMA, Yogi Pasca. Do the rate of profit and organic composition in Central Java Industry increase in the long run? A test of heterodox political economy perspective. Journal of Emerging Issues in Economics, Finance and Banking (JEIEFB), vol. 3, n. 6, 2014.

SHAIKH, A. The first Great Depression of the 21st century. Socialist Register, 2011. Disponível em: https://socialistregister.com/index.php/srv/article/view/14330.

WEISSKOPF, Thomas E. Marxian crisis theory and the rate of profit in the postwar US economy. Cambridge Journal of Economics, vol. 3, n. 4, 1979. DOI: https://doi.org/10.1093/oxfordjournals.cje.a035429 